CLINICAL STUDY

\title{
Association of serum fetuin A with truncal obesity and dyslipidemia in non-diabetic hemodialysis patients
}

\author{
Hung-Yuan Chen ${ }^{1,2}$, Yen-Lin Chiu ${ }^{1,2}$, Shih-Ping Hsu ${ }^{1,2}$, Mei-Fen Pai ${ }^{1,2}$, Chun-Fu Lai ${ }^{1,2}$, Yu-Sen Peng ${ }^{1,2}$, \\ Tze-Wah Kao ${ }^{2}$, Kuan-Yu Hung ${ }^{2}$, Tun-Jun Tsai ${ }^{2}$ and Kwan-Dun $\mathrm{Wu}^{2}$ \\ ${ }^{1}$ Division of Nephrology, Department of Internal Medicine, Far Eastern Memorial Hospital, 21, Nan-Ya S. Road, Sec. 2 Pan-Chiao, Taipei 200, Taiwan ROC \\ and ${ }^{2}$ Division of Nephrology, Department of Internal Medicine, National Taiwan University Hospital and National Taiwan University College of Medicine, \\ No. 7, Chung-Shan South Road, Taipei 100, Taiwan ROC \\ (Correspondence should be addressed to K-Y Hung; Email: kyhung@ntu.edu.tw)
}

\begin{abstract}
Background: Fetuin A, a predictor of cardio-vascular (CV) mortality in dialysis patients has been associated with dyslipidemia in non-diabetic coronary artery disease. Truncal obesity is linked to dyslipidemia and also predicts CV mortality. This study had aimed to investigate the associations among fetuin A, truncal obesity, and dyslipidemia in hemodialysis (HD) patients.

Methods: One hundred and nine non-diabetic HD patients were evaluated. Waist circumference, highly sensitive C-reactive protein (hs-CRP), fetuin A, and lipoprotein levels (i.e. total cholesterol (T-CHO), low-density lipoprotein (LDL-C), high-density lipoprotein (HDL-C), non-HDL-C, and triglyceride (TG)) were measured for analysis of correlations. The patients were divided into tertiles by fetuin A concentrations.

Results: Data from 63 women and 46 men aged $60 \pm 13$ years were analyzed. Patients in the highest tertile of fetuin A $(0.33-0.51 \mathrm{~g} / \mathrm{l})$ had higher serum creatinine, albumin, T-CHO, LDL-C, non-HDL-C, and TG, more truncal obesity and lower hs-CRP than patients in the lowest tertile (all $P<0.05)$. In multi-variable linear regression analysis, fetuin A was independently associated with TG level and total iron binding capacity after adjustments for age, hemoglobin, albumin, calcium, body mass index, and hs-CRP. Patients in the highest fetuin A tertile had 3.2- and 4.4-fold higher incidence of truncal obesity $(P=0.038)$ and hyper-triglyceridemia $(P=0.015)$ independent of nutritional status and inflammation.

Conclusion: Fetuin A is positively associated with truncal obesity and dyslipidemia, which are independent of malnutrition and inflammation. It may predict visceral adiposity and dyslipidemia, especially TG and TG-rich lipoproteins, in HD patients.
\end{abstract}

European Journal of Endocrinology 160 777-783

\section{Introduction}

Fetuin A is a protein secreted by hepatocytes that inhibits insulin receptor tyrosine kinase of adipose and muscle cells $(1,2)$. Recently, its inhibitory potency on calcium phosphate precipitation has been linked to cardio-vascular (CV) calcification and has predicted CV and non-CV mortality in dialysis patients (3). In an animal model, mice with fatty liver up-regulated fetuin A $(A h s g)$ mRNA $(4,5)$. Moreover, in a recent investigation, fetuin A concentration was associated with body fat mass in chronic kidney disease (CKD) patients (6). This suggests that fetuin A may play a role in deranged visceral adiposity in both humans and mice.

Truncal obesity, known as an over-accumulation of visceral adiposity that can be estimated by waist circumference (WC), is prevalent in hemodialysis (HD) patients $(7,8)$. It is closely related to non-alcoholic hepatic steatosis, epicardial fat deposition, and insulin resistance (IR), and predicts the occurrence of type 2 diabetes mellitus (DM) in the general population (9-12). Furthermore, deranged visceral adiposity consequently leads to inflammation, dyslipidemia (13), and higher CV mortality. Unfortunately, the association of fetuin A and truncal obesity in HD patients prone to fetuin A deficiency and malnutrition has not yet been investigated.

In non-diabetic coronary artery disease (CAD) patients without CKD, fetuin A concentration is closely associated with dyslipidemia, especially high-density lipoprotein cholesterol (HDL-C), triglyceride (TG), and low-density lipoprotein cholesterol (LDL-C) (4). In previous investigations, chronic dialysis patients frequently have low HDL-C and LDL-C levels than the general population and predict worse all-cause outcomes $(14,15)$. Although the prevalence of dyslipidemia is extremely high in dialysis patients, the exact relationship of fetuin $A$ and dyslipidemia in these patients is unknown. 
This study posits that the fetuin A may be associated with the derangement of visceral adiposity and consequently, dyslipidemia in dialysis patients. This cross-sectional investigation aimed to reveal the relationships among fetuin A, atherogenic lipoproteins, and truncal obesity in non-diabetic HD patients.

\section{Methods}

\section{Subjects and patients}

One hundred and nine patients aged $>18$ years (mean age: $60 \pm 13$ years; 63 females) who received HD for more than six months at the Far Eastern Memorial Hospital were evaluated for analysis of fetuin A, WC, and lipid profiles. Diabetic patients with a past history and/or present fasting hyperglycemia $\geq 126 \mathrm{mg} / \mathrm{dl}$ were excluded. One hundred and thirty-four nondiabetic patients were initially included but eight with active infection, two who were hospitalized for acute ischemic stroke and who received trans-arterial chemoembolization for hepatocellular carcinoma, and 15 who refused to participate were excluded. Data from 109 patients were included in the final analysis.

The study patients received 3.5-5 h of HD three times a week using bicarbonate dialysate. The mean duration of HD before recruitment was 4.1 years (range: $0.8-$ 19.5 years). Fifty-seven women were post-menopausal (91\%). The hospital's Institutional Review Board approved this study and all of the participants provided written informed consent.

\section{Baseline demographic and clinical data and Iaboratory parameters}

Baseline data, including gender, age, body weight and height, body mass index (BMI), WC, presence of hypertension, underlying renal disease, HD regimen, duration of HD therapy, and concurrent medications of each patient were recorded.

WC was measured on bare skin at the level of the umbilicus. Truncal obesity was defined according to the modified Asian criteria of the National Cholesterol Education Program Adult Treatment Panel III (NCEP ATP III), i.e., WC $>90 \mathrm{~cm}$ in males and $>80 \mathrm{~cm}$ in females (16).

Venous blood was sampled in the morning, after an overnight fast $>8 \mathrm{~h}$ before dialysis. Whole blood was used for measuring hemoglobin, EDTA-plasma for blood urea nitrogen, serum creatinine, calcium, phosphorus, potassium, uric acid, albumin, TG, total cholesterol (T-CHO), LDL-C, HDL-C, and non-HDL-C.

Immuno-assay determined intact parathyroid hormone while the immuno-nephelometric method using Tina-quant CRP (Latex, Indianapolis, IN, USA) ultra-sensitive assay (D \& P modular analyzer, Roche Diagnostics $\mathrm{GmbH}$ ) determined the highly sensitive C-reactive protein (hs-CRP).

\section{Measurements of serum fetuin A concentration}

Serum fetuin A was measured by a highly sensitive, twosite enzyme linked with immuno-assay (GenWay Biotech, Inc., San Diego, CA, USA). Nephelometry for fetuin A employed the same high-specificity antibody as the ELISA and established reproducible standard curves after testing for appropriate dilution. This was evaluated in a side-by-side comparison with immuno-blot analysis to exclude cross-reactivity of the antibodies with other serum proteins and proteolytic fragments of fetuin A. The intra-assay coefficient of variation was $5.5 \%$ and the inter-assay coefficient of variation was $6.2 \%$. The assay linear measurement range of human fetuin A was $0.05-3.5 \mathrm{~g} / \mathrm{l}$.

\section{Lipoprotein measurement}

Levels of T-CHO and TG were measured enzymatically while HDL-C was measured after precipitating apolipoprotein B-containing lipoproteins with dextran sulfate and magnesium chloride. LDL-C was calculated according to the Friedwald formula, with non-HDL-C equal to T-CHO minus HDL-C.

\section{Statistical analysis}

Continuous data are presented as mean \pm s.D. while categorical data are reported as percentages. The participants were divided into tertiles based on serum fetuin A concentrations, with tertile 1 representing the lowest tertile (tertile $1: 0.15-0.25$, tertile $2: 0.26-0.32$, and tertile 3: $0.32-0.51 \mathrm{~g} / \mathrm{l})$. Differences in baseline characteristics and lipoprotein concentrations were compared by ANOVA and LSD post hoc analysis for continuous variables, and by $\chi^{2}$ test for categorical variables. The unadjusted association of fetuin A with WC and lipoproteins was also evaluated using Pearson's correlation.

Linear regression analyses determined the adjusted association of fetuin A and all other variables. Fetuin A was the dependent variable and in addition to demographic characteristics (e.g. age), covariates for multi-variable adjustment were selected based on the reported association with fetuin A (i.e. albumin, hemoglobin, hs-CRP, BMI, and calcium) in previously published results $(3,17,18)$.

The association of fetuin A tertiles with truncal obesity and components of dyslipidemia were also evaluated. Logistic regression models were used, with fetuin $\mathrm{A}$ as the predictor variable and dyslipidemia (i.e. serum T-CHO $\geq 200 \mathrm{mg} / \mathrm{dl}$, LDL-C $\geq 130 \mathrm{mg} / \mathrm{dl}$, $\mathrm{HDL}-\mathrm{C} \leq 40 \mathrm{mg} / \mathrm{dl}$ in men and $\leq 50 \mathrm{mg} / \mathrm{dl}$ in women, non-HDL-C $\geq 160 \mathrm{mg} / \mathrm{dl}$, and TG $\geq 150 \mathrm{mg} / \mathrm{dl}$ ) (16) as a separate outcome variable. These models were adjusted for the same covariates as the primary multivariable models. All statistical analyses were performed 
using the SPSS software, version 13.0 (SPSS, Inc., Chicago, IL, USA). A $P$ value $<0.05$ was considered statistically significant.

\section{Results}

\section{Basic characteristics and truncal obesity among tertiles of fetuin $A$}

The basic characteristics of patients in different tertiles of fetuin A were summarized in Table 1. Their means of fetuin A concentration were $0.21 \pm 0.03,0.28 \pm 0.02$, and $0.37 \pm 0.05 \mathrm{~g} / \mathrm{l}$ respectively, which were normally distributed (mean $0.29 \pm 0.07 \mathrm{~g} / \mathrm{l}$ ). Patients in the highest tertile were younger than those in the middle $(P=0.022)$ and lowest tertile $(P=0.001)$, had higher serum creatinine than those in the middle $(P=0.043)$ and lowest tertile $(P=0.013)$; higher albumin than those in the middle $(P=0.013)$ and the lowest tertile $(P<0.001)$; and lower hs-CRP than those in the lowest tertile $(P=0.017)$ but similar to those in the middle tertile $(P=0.142)$. The WC and BMI of patients in the tertiles were similar, although more patients in the highest tertile had truncal obesity than those in the middle $(P=0.042)$ and the lowest tertiles $(P=0.012)$.
Men had similar age, BMI, albumin, hs-CRP, fetuin A, and hemoglobin as women in the study, but had higher serum creatinine, body weight, and height than the women.

\section{Lipoprotein levels in tertiles of fetuin $A$}

The means of T-CHO, LDL-C, HDL-C, non-HDL-C, and TG in all the patients were $177 \pm 44$, $94 \pm 36$, $55.8 \pm 17.5,122 \pm 40$, and $141 \pm 93 \mathrm{mg} / \mathrm{dl}$ respectively. Serum T-CHO, LDL-C, non-HDL-C, and TG levels were different among the tertiles $(P=0.001,0.011$, 0.001 , and 0.036 respectively). Patients in the highest tertile had higher TG levels than those in the lowest tertile $(P=0.023)$ but similar levels to those in the middle tertile $(P=0.130)$; higher T-CHO than those in the middle $(P=0.020)$ and the lowest tertiles $(P=0.014)$; higher LDL-C than those in the middle $(P=0.048)$ and the lowest tertiles $(P=0.010)$; and higher non-HDL-C than those in the middle $(P=0.044)$ and the lowest tertiles $(P=0.023)$. HDL-C levels were not different among the tertiles (Fig. 1 and Table 2). In the highest tertile of fetuin A concentration, patients had more TG $>150 \mathrm{mg} / \mathrm{dl}$ and non-HDL-C $>160 \mathrm{mg} / \mathrm{dl}$ than those in the two other tertiles (Table 2).

Table 1 Basic characteristics of patients in tertiles of fetuin A concentration.

\begin{tabular}{|c|c|c|c|c|c|}
\hline & \multirow[b]{2}{*}{$\begin{array}{l}\text { All patients } \\
n=109\end{array}$} & \multicolumn{3}{|c|}{ Fetuin A tertile $(\mathrm{g} / \mathrm{l})$} & \multirow[b]{2}{*}{$P$ value } \\
\hline & & $\begin{array}{l}0.15-0.25 \\
n=36\end{array}$ & $\begin{array}{l}0.26-0.32 \\
n=37\end{array}$ & $\begin{array}{l}0.33-0.51 \\
n=36\end{array}$ & \\
\hline Age (year) & $60 \pm 13$ & $65 \pm 13$ & $59 \pm 12$ & $54 \pm 12$ & 0.001 \\
\hline Gender (woman \%) & 58 & 64 & 50 & $69^{-1}$ & 0.219 \\
\hline Dialysis duration (year) & $4.4 \pm 3.5$ & $4.8 \pm 4.3$ & $4.5 \pm 3.5$ & $4.2 \pm 2.6$ & 0.815 \\
\hline $\mathrm{Kt} / \mathrm{V}_{\text {urea }}$ & $1.32 \pm 0.18$ & $1.33 \pm 0.19$ & $1.31 \pm 0.18$ & $1.31 \pm 0.19$ & 0.902 \\
\hline $\mathrm{BMI}$ & $22.2 \pm 2.8$ & $21.7 \pm 3.1$ & $22.4 \pm 2.6$ & $22.4 \pm 2.8$ & 0.503 \\
\hline Waist circumference $(\mathrm{cm})$ & $82 \pm \overline{9}$ & $81 \pm \overline{11}$ & $84 \pm 10$ & $82 \pm \overline{7}$ & 0.528 \\
\hline \multicolumn{6}{|l|}{ Laboratory data } \\
\hline Creatinine (mg/dl) & $11.0 \pm 2.2$ & $10.2 \pm 2.3$ & $11.5 \pm 2.3$ & $11.6 \pm 1.7$ & 0.022 \\
\hline Hemoglobin ( $\mathrm{g} / \mathrm{dl})$ & $10.9 \pm 1.4$ & $10.5 \pm 1.3$ & $11.1 \pm 1.6$ & $10.9 \pm 1.2$ & 0.193 \\
\hline Uric acid $(\mathrm{mg} / \mathrm{dl})$ & $7.7 \pm 1.3$ & $7.4 \pm 1.3$ & $7.8 \pm 1.3$ & $7.8 \pm 1.3$ & 0.418 \\
\hline $\mathrm{Na}(\mathrm{mmol} / \mathrm{l})$ & $145 \pm 3$ & $144 \pm 3$ & $144 \pm 3$ & $145 \pm 2$ & 0.672 \\
\hline $\mathrm{K}(\mathrm{mmol} / \mathrm{l})$ & $4.9 \pm 0.7$ & $4.9 \pm 0.8$ & $4.8 \pm 0.8$ & $4.9 \pm 0.6$ & 0.656 \\
\hline $\mathrm{Ca}(\mathrm{mg} / \mathrm{dl})$ & $9.2 \pm 0.7$ & $9.1 \pm 0.9$ & $9.2 \pm 0.7$ & $9.3 \pm 0.6$ & 0.338 \\
\hline $\mathrm{P}(\mathrm{mg} / \mathrm{dl})$ & $5.4 \pm 1.2$ & $5.3 \pm 1.4$ & $5.2 \pm 1.1$ & $5.6 \pm 1.0$ & 0.465 \\
\hline CaxP & $50 \pm 12$ & $49 \pm 16$ & $48 \pm 10$ & $52 \pm 10$ & 0.357 \\
\hline iPTH (pg/ml) & $429 \pm 389$ & $47 \overline{9} \pm 422$ & $373 \pm 319$ & $43 \overline{4} \pm 421$ & 0.548 \\
\hline hs-CRP (mg/dl) & $0.8 \pm 1.5$ & $1.1 \pm 1.9$ & $0.9 \pm 1.7$ & $0.4 \pm 0.4$ & 0.087 \\
\hline \multicolumn{6}{|l|}{ Nutritional parameters } \\
\hline Albumin (g/l) & $4.2 \pm 0.4$ & $3.9 \pm 0.5$ & $4.2 \pm 0.3$ & $4.3 \pm 0.3$ & $<0.001$ \\
\hline TIBC (mg/dl) & $212 \pm 46$ & $184 \pm 33$ & $220 \pm 38$ & $230 \pm 51$ & $<0.001$ \\
\hline nPCR (g/kg per day) & $1.2 \pm 0.3$ & $1.2 \pm 0.3$ & $1.2 \pm 0.3$ & $1.2 \pm 0.3$ & 0.598 \\
\hline Truncal obesity $(\%)$ & $41(37.6)$ & $8(22.2)$ & $14(37.8)$ & $19(52.8)$ & 0.009 \\
\hline \multicolumn{6}{|l|}{ Medications (\%) } \\
\hline Statins & $26(23.8)$ & $8(22.2)$ & $8(21.6)$ & $10(27.8)$ & 0.189 \\
\hline Anti-hypertensive agents & $54(49.5)$ & $17(47.2)$ & $18(48.6)$ & $19(52.8)$ & 0.687 \\
\hline Aspirin/NSAID & $21(19.3)$ & $7(19.4)$ & $8(21.6)$ & $6(16.7)$ & 0.588 \\
\hline
\end{tabular}

BMI, body mass index; Na, sodium; $\mathrm{K}$, potassium; $\mathrm{Ca}$, calcium; $\mathrm{P}$, phosphorus; CaxP, calcium phosphate product; iPTH, intact parathyroid hormone; hs-CRP, highly sensitive C-reactive protein; TIBC, total iron binding capacity; nPCR, normalized protein catabolic rate; Statins, HMG-CoA reductase inhibitors; NSAID, non-steroid anti-inflammatory drugs.

${ }^{a}$ Waist circumference $>90 \mathrm{~cm}$ in men and $>80 \mathrm{~cm}$ in women. 

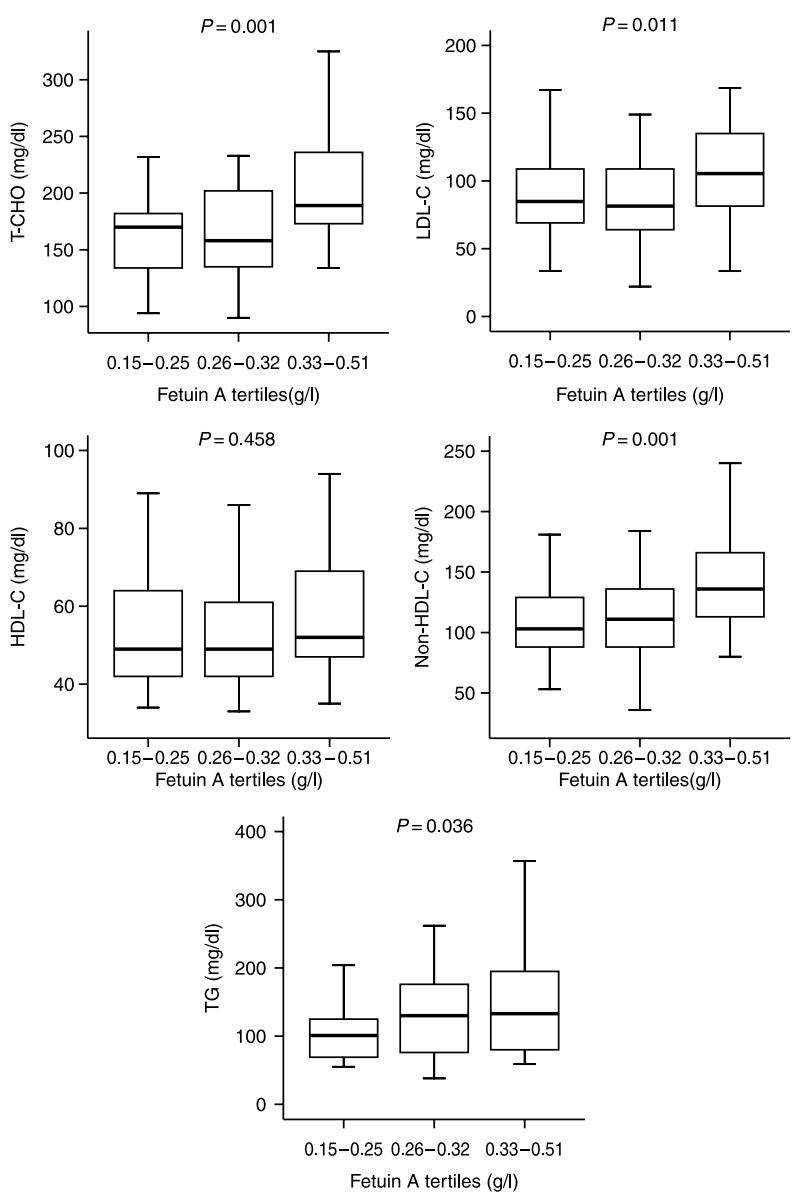

Figure 1 Serum T-CHO, LDL-C, non-HDL-C, and TG levels were higher in the highest tertile $(P=0.001,0.011,0.001$, and 0.036 respectively), while HDL-C levels were not different among the tertiles $(P=0.458)$.

Association between fetuin A, lipoproteins, and truncal obesity

In univariate analysis, the association of demographic variables and lipoproteins with fetuin A was linear. Age, hemoglobin, creatinine, calcium, log (hs-CRP), albumin, total iron binding capacity (TIBC), T-CHO, nonHDL-C, and TG were likewise significantly associated with fetuin A concentrations (Table 3).

In multi-variate analysis, after adjustment for variables associated with fetuin $A$, only age, albumin, TIBC, and TG were independently significantly correlated with fetuin A $(P=0.032,<0.001,0.018$, and 0.038 respectively).

\section{Association of truncal obesity and dyslipidemia with fetuin $A$}

The highest tertile of fetuin A was significantly associated with more truncal obesity and higher nonHDL-C and TG levels compared with the lowest tertile ( $P=0.021,0.04$, and 0.023 respectively). After multi-variate adjustments for age, albumin, calcium, BMI and hs-CRP levels, fetuin A remained associated with truncal obesity and TG levels (odd ratio $=3.2$ and $4.4, P=0.038$ and 0.015 respectively; Table 4 ).

\section{Discussion}

The present investigation mainly demonstrates that fetuin A concentrations in non-diabetic HD patients are positively associated with truncal obesity and dyslipidemia, especially hypertriglyceridemia, which are independent of nutritional status and inflammation. Beyond an inhibitory potency on CV calcification, higher fetuin $\mathrm{A}$ is also linked to deranged visceral adiposity in non-diabetic HD patients, similar to the general population. Regarding the association of type 2 diabetes and dyslipidemia with fetuin $A$ in the general population $(4,19)$, the results here show connections in $\mathrm{HD}$ patients.

Truncal obesity is associated with enhanced adipokine secretion and results in dyslipidemia and consequently, DM in obese populations. It is also closely linked to non-alcoholic hepatic steatosis and CV diseases (9-12). Here, a novel association between truncal obesity and fetuin A concentrations is demonstrated in the HD population, many of whom are prone to be thinner and have lower BMI. The mechanisms underlying this connection remain unknown although in animals, rats with fatty liver expressed up-regulated fetuin A mRNA (20). Moreover, in a non-CKD human longitudinal study, fetuin A concentration is positively associated with liver fat (5).

Because fetuin A is exclusively secreted from hepatocytes, it is hypothesized that fetuin A expression is up-regulated in liver dysfunction, especially fatty liver (5), which may be the go-between of truncal obesity and high fetuin A concentration in HD patients. However, the exact amount of liver fat was not measured in the present investigation. As regards the close association of fatty liver and truncal obesity (21), it is suggested that patients with high fetuin A concentrations have more severe fatty liver. This, however, requires further evaluation to validate.

In the results here, high fetuin A concentration is independently predictive of truncal obesity (Table 3) even after adjustments for albumin, creatinine, hemoglobin levels, BMI, and age. This implicates high fetuin A to subsequent complications of truncal obesity, such as type $2 \mathrm{DM}$ and $\mathrm{CV}$ diseases. Interestingly, higher fetuin $\mathrm{A}$ is linked to the incidence of type $2 \mathrm{DM}$ in the elderly. Nevertheless, in dialysis patients prone to renal IR, the association of fetuin A and DM may be difficult to establish.

Contrary to the general perception, lower BMI predicts higher mortality in end-stage renal disease (ESRD), which is the so-called 'reverse epidemiology' in 
Table 2 Lipoprotein concentrations and dyslipidemia of patients in tertiles of fetuin A concentration.

\begin{tabular}{|c|c|c|c|c|c|}
\hline & \multirow[b]{2}{*}{$\begin{array}{l}\text { All patients } \\
n=109\end{array}$} & \multicolumn{3}{|c|}{ Fetuin A tertile $(\mathrm{g} / \mathrm{l})$} & \multirow[b]{2}{*}{$P$ value } \\
\hline & & $\begin{array}{l}0.15-0.25 \\
n=36\end{array}$ & $\begin{array}{l}0.26-0.32 \\
n=37\end{array}$ & $\begin{array}{l}0.33-0.51 \\
n=36\end{array}$ & \\
\hline \multicolumn{6}{|l|}{ Lipoproteins } \\
\hline $\mathrm{TG}(\mathrm{mg} / \mathrm{dl})$ & $141 \pm 93$ & $111 \pm 46$ & $142 \pm 98$ & $170 \pm 112$ & 0.036 \\
\hline $\mathrm{T}-\mathrm{CHO}(\mathrm{mg} / \mathrm{dl})$ & $177 \pm 44$ & $169 \pm 37$ & $166 \pm 41$ & $201 \pm 46$ & 0.001 \\
\hline LDL-C (mg/dl) & $94 \pm 36$ & $89 \pm 30$ & $84 \pm 33$ & $108 \pm 39$ & 0.011 \\
\hline Non-HDL-C (mg/dl) & $122 \pm 40$ & $11 \overline{1} \pm 32$ & $11 \overline{3} \pm 38$ & $142 \pm 42$ & 0.001 \\
\hline $\mathrm{HDL}-\mathrm{C}(\mathrm{mg} / \mathrm{dl})$ & $56 \pm 17$ & $55 \pm 18$ & $54 \pm 17$ & $59 \pm 18$ & 0.458 \\
\hline \multicolumn{6}{|l|}{ Dyslipidemia } \\
\hline $\mathrm{TG}>150 \mathrm{mg} / \mathrm{dl}$ & $38(34.9)$ & $7(19.4)$ & $11(29.7)$ & $20(55.6)$ & 0.003 \\
\hline $\mathrm{T}-\mathrm{CHO} \geq 200 \mathrm{md} / \mathrm{dl}$ & $28(25.7)$ & $6(16.7)$ & $10(27.0)$ & $12(33.3)$ & 0.128 \\
\hline $\mathrm{LDL}-\mathrm{C} \geq 130 \mathrm{mg} / \mathrm{dl}$ & $18(16.5)$ & $4(11.1)$ & $4(10.8)$ & $10(27.8)$ & 0.088 \\
\hline Non-HDL-C > $160 \mathrm{mg} / \mathrm{dl}$ & $19(17.4)$ & $3(8.3)$ & $6(16.2)$ & $10(27.8)$ & 0.017 \\
\hline Low HDL-C & 37 (37.4) & $14(42.4)$ & $13(39.4)$ & $10(30.3)$ & 0.571 \\
\hline
\end{tabular}

TG, triglyceride; T-CHO, total cholesterol; LDL-C, low-density lipoprotein; IFG, non-HDL-C, non- high-density lipoprotein; HDL-C, high-density lipoprotein. ${ }^{\mathrm{a}} \mathrm{HDL}-\mathrm{C}<40 \mathrm{mg} / \mathrm{dl}$ in men or $<50 \mathrm{mg} / \mathrm{dl}$ in women.

dialysis patients (22). While there is still controversy about the 'reverse epidemiology', the present evidences support this phenomenon. Other than bio-incompatibility and oxidative stress in dialysis patients, malnutrition-inflammation-anemia syndrome is the major cause of inflammation $(22,23)$. In previous investigations, there was a negative correlation between serum fetuin A concentration and hs-CRP, which is compatible with our results $(3,24)$. The exact mechanism of the low inflammatory status in dialysis patients with higher fetuin A concentration is not completely known. Nonetheless, some authors propose the potency of fetuin A in inhibiting vascular

Table 3 Association of fetuin A concentration with other variables.

\begin{tabular}{|c|c|c|c|c|}
\hline \multirow[b]{2}{*}{ Measurements } & \multicolumn{2}{|c|}{ Univariable analysis } & \multicolumn{2}{|c|}{$\begin{array}{l}\text { Multivariable } \\
\text { analysis }^{\mathrm{a}}\end{array}$} \\
\hline & $\beta$ & $P$ values & $\beta$ & $P$ values \\
\hline Age & -0.376 & $<0.001$ & -0.211 & 0.032 \\
\hline Hemoglobin & 0.185 & 0.036 & & \\
\hline Creatinine & 0.262 & 0.005 & & \\
\hline Calcium & 0.204 & 0.042 & & \\
\hline BMI & 0.083 & 0.414 & & \\
\hline Log (hs-CRP) & -0.283 & 0.013 & & \\
\hline \multicolumn{5}{|c|}{ Nutritional parameters } \\
\hline Albumin & 0.514 & $<0.001$ & 0.451 & $<0.001$ \\
\hline TIBC & 0.404 & $<0.001$ & 0.242 & 0.018 \\
\hline nPCR & 0.078 & 0.446 & & \\
\hline \multicolumn{5}{|l|}{ Lipoproteins } \\
\hline $\mathrm{T}-\mathrm{CHO}$ & 0.249 & 0.043 & & \\
\hline LDL-C & 0.171 & 0.089 & & \\
\hline HDL-C & 0.045 & 0.661 & & \\
\hline Non-HDL-C & 0.255 & 0.011 & 0.192 & 0.068 \\
\hline TG & 0.221 & 0.005 & 0.234 & 0.038 \\
\hline
\end{tabular}

BMI, body mass index; hs-CRP, highly sensitive C-reactive protein; TIBC, total iron binding capacity; $\mathrm{nPCR}$, normalized protein catabolic rate; $\mathrm{T}-\mathrm{CHO}$ total cholesterol; LDL-C, low-density lipoprotein; HDL-C, high-density lipoprotein; non-HLD-C, non-high-density lipoprotein; TG, triglyceride.

adjusted for age, hemoglobin, albumin, calcium, BMI, and hs-CRP. calcification and in the negative acute phase protein as its anti-inflammatory effects $(18,25)$. Beyond the accelerated vascular calcium deposition in fetuin A deficiency, the associated lower visceral adiposity may be another explanation for the high CV mortality. Further investigations are again warranted.

The association of fetuin A and dyslipidemia is observed in non-diabetic CAD patients. Fetuin A is positively associated with LDL-C, non-HDL-C, and TG but negatively associated with HDL-C. The association is explained by the inhibitory effect of fetuin A on adipose tissue, which leads to lipolysis and free fatty acid efflux (4). In animal models, the over-expression of hepatic Neu3, a membrane enzyme linked to insulin sensitivity, increases hepatic TG accumulation and fetuin A expression (26). The secretion of fetuin A and TG may be a phenomenon that occurs simultaneously to common stimulations in hepatocytes.

The present study also demonstrates an association between fetuin A and non-HDL-C, mainly composed of TG-rich lipoproteins (27), and TG but not LDL-C and HDL-C in HD patients (Tables 3 and 4). Several investigations, including the present one, have shown that ESRD patients mainly have more elevated TG and non-HDL-C but not LDL-C $(14,28)$. This may partially explain why the association between fetuin $\mathrm{A}$ and dyslipidemia occurs mainly on the non-HDL-C and TG components. On the relationship between dyslipidemia and CV mortality (29-31), the relationship between high fetuin $\mathrm{A}$ and $\mathrm{CV}$ mortality warrants further investigation through larger studies because its reverse impact on CV mortality related to malnutrition and CV calcification in dialysis patients has been shown in previous studies $(3,18)$.

This study has some limitations. First, the relatively small size of HD patients cannot completely resolve the epidemiologic question. Particularly, on multi-variable regression analysis, not all possible confounding factors 
Table 4 Association of fetuin A tertiles with truncal obesity and dyslipidemia.

\begin{tabular}{|c|c|c|c|c|c|c|}
\hline & \multicolumn{5}{|c|}{ Fetuin A tertiles $(\mathrm{g} / \mathrm{l})$} & \multirow[b]{3}{*}{$P$ value } \\
\hline & \multirow{2}{*}{$\begin{array}{l}0.15-0.25 \\
\text { Reference }\end{array}$} & \multicolumn{2}{|c|}{$0.26-0.32$} & \multicolumn{2}{|c|}{$0.33-0.51$} & \\
\hline & & OR & $95 \% \mathrm{Cl}$ & OR & $95 \% \mathrm{Cl}$ & \\
\hline \multicolumn{7}{|l|}{ Unadjusted } \\
\hline Truncal obesity $^{a}$ & 1 & 2.7 & $0.9-8.1$ & 3.1 & $1.1-9.1$ & 0.021 \\
\hline $\mathrm{TG} \geq 150 \mathrm{mg} / \mathrm{dl}$ & 1 & 1.9 & $0.6-5.6$ & 3.5 & $1.2-10.3$ & 0.023 \\
\hline $\mathrm{T}-\mathrm{CHO} \geq 200 \mathrm{md} / \mathrm{dl}$ & 1 & 1.9 & $0.6-6.2$ & 2.6 & $0.8-8.0$ & 0.103 \\
\hline LDL-C $\geq 130 \mathrm{mg} / \mathrm{dl}$ & 1 & 0.7 & $0.1-3.5$ & 3.2 & $0.9-11.4$ & 0.079 \\
\hline $\begin{array}{l}\mathrm{HDL}<40 \mathrm{mg} / \mathrm{dl} \text { in men or } \\
<50 \mathrm{mg} / \mathrm{dl} \text { in women }\end{array}$ & 1 & 0.9 & $0.3-2.4$ & 0.6 & $0.2-1.6$ & 0.308 \\
\hline $\begin{array}{l}\text { Non-HDL-C> }>160 \mathrm{mg} / \mathrm{dl} \\
\text { Adjusted }^{\mathrm{b}}\end{array}$ & 1 & 2.2 & $0.5-9.8$ & 4.3 & $1.1-17.6$ & 0.04 \\
\hline Truncal obesity & 1 & 2.8 & $0.9-8.9$ & 3.2 & $1.1-9.7$ & 0.038 \\
\hline $\mathrm{TG} \geq 150 \mathrm{mg} / \mathrm{dl}$ & 1 & 2.1 & $0.7-7.5$ & 4.4 & $1.4-14.2$ & 0.015 \\
\hline
\end{tabular}

TG, triglyceride; T-CHO, total cholesterol; LDL-C, low-density lipoprotein; HDL-C, high-density lipoprotein; non-HLD-C, non-high-density lipoprotein; OR, odds ratio; $\mathrm{Cl}$, confidence interval.

aWaist circumference $>90 \mathrm{~cm}$ in men and $>80 \mathrm{~cm}$ in women.

${ }^{b}$ Covariates for multi-variable adjustment included age, hemoglobin, albumin, calcium, BMI, and hs-CRP.

of fetuin A could be selected for adjustment. Hence, the statistical power could have been weakened. Second, the cross-sectional design cannot resolve the problem of causal relationship. Further longitudinal change of visceral adiposity and fetuin A level should be investigated thereafter. Third, the exact visceral adiposity was not measured directly, which lessened the evidence regarding the association between fetuin $\mathrm{A}$ and truncal obesity.

\section{Conclusions}

This cross-sectional investigation demonstrates the positive association of fetuin A with truncal obesity and dyslipidemia, especially hyper-triglyceridemia, which are independent of malnutrition and inflammation. Fetuin A may be a good predictive marker of visceral adiposity in non-diabetic HD patients with a relatively lean body size, and of dyslipidemia, especially TG and TG-rich lipoproteins. Further larger scale studies are needed to corroborate these findings.

\section{Declaration of interest}

There is no conflict of interest that could be perceived as prejudicing the impartiality of the research reported.

\section{Funding}

This research did not receive any specific grant from any funding agency in the public, commercial or not-for-profit sector.

\section{Acknowledgements}

The authors express their thanks to the Ta-Tung Kidney Foundation and the Mrs Hsin-Chin Lee Kidney Research Fund for supporting this study.

\section{References}

1 Kalabay L, Chavin K, Lebreton JP, Robinson KA, Buse MG \& Arnaud P. Human recombinant alpha 2-HS glycoprotein is produced in insect cells as a full length inhibitor of the insulin receptor tyrosine kinase. Hormone and Metabolic Research 1998 30 1-6.

2 Rauth G, Poschke O, Fink E, Eulitz M, Tippmer S, Kellerer M, Haring HU, Nawratil P, Haasemann M, Jahnen-Dechent W \& Muller-Esterl W. The nucleotide and partial amino acid sequences of rat fetuin. Identity with the natural tyrosine kinase inhibitor of the rat insulin receptor. European Journal of Biochemistry 1992204 523-529.

3 Hermans MM, Brandenburg V, Ketteler M, Kooman JP, van der Sande FM, Boeschoten EW, Leunissen KM, Krediet RT \& Dekker FW. Association of serum fetuin-A levels with mortality in dialysis patients. Kidney International 200772 202-207.

4 Ix JH, Shlipak MG, Brandenburg VM, Ali S, Ketteler M \& Whooley MA. Association between human fetuin-A and the metabolic syndrome: data from the Heart and Soul Study. Circulation 2006113 1760-1767.

5 Stefan N, Hennige AM, Staiger H, Machann J, Schick F, Krober SM, Machicao F, Fritsche A \& Haring HU. Alpha2-Heremans-Schmid glycoprotein/fetuin-A is associated with insulin resistance and fat accumulation in the liver in humans. Diabetes Care 200629 853-857.

6 Axelsson J, Wang X, Ketteler M, Qureshi AR, Heimburger O, Barany P, Lindholm B, Nordfors L \& Stenvinkel P. Is fetuin-A/ alpha2-Heremans-Schmid glycoprotein associated with the metabolic syndrome in patients with chronic kidney disease? American Journal of Nephrology 200828 669-676.

7 Tsangalis G, Papaconstantinou S, Kosmadakis G, Valis D \& Zerefos N. Prevalence of the metabolic syndrome in hemodialysis. International Journal of Artificial Organs 200730 118-123.

8 Yang SY, Chiang CK, Hsu SP, Peng YS, Pai MF, Ho TI, Hung KY \& $\mathrm{Wu}$ KD. Metabolic syndrome predicts hospitalization in hemodialysis patients: a prospective Asian cohort study. Blood Purification 200725 252-259.

9 Balkau B, Deanfield JE, Despres JP, Bassand JP, Fox KA, Smith SC Jr, Barter P, Tan CE, Van Gaal L, Wittchen HU, Massien C \& Haffner SM. International day for the evaluation of abdominal obesity (IDEA): a study of waist circumference, cardiovascular disease, and diabetes mellitus in 168,000 primary care patients in 63 countries. Circulation 2007116 1942-1951. 
10 Janiszewski PM, Janssen I \& Ross R. Does waist circumference predict diabetes and cardiovascular disease beyond commonly evaluated cardiometabolic risk factors? Diabetes Care $2007 \mathbf{1 2}$ 3105-3109.

11 Sobhonslidsuk A, Jongjirasiri S, Thakkinstian A, Wisedopas N, Bunnag P \& Puavilai G. Visceral fat and insulin resistance as predictors of non-alcoholic steatohepatitis. World Journal of Gastroenterology 200713 3614-3618.

12 Iacobellis G, Assael F, Ribaudo MC, Zappaterreno A, Alessi G, Di Mario U \& Leonetti F. Epicardial fat from echocardiography: a new method for visceral adipose tissue prediction. Obesity Research 200311 304-310.

13 Vega GL, Adams-Huet B, Peshock R, Willett D, Shah B \& Grundy SM. Influence of body fat content and distribution on variation in metabolic risk. Journal of Clinical Endocrinology and Metabolism 2006 91 4459-4466.

14 Chen HY, Kao TW, Huang JW, Tsai TJ \& Wu KD. Association between dyslipidemia and residual renal function in patients on chronic peritoneal dialysis. Clinical Nephrology $2008 \mathbf{7 0}$ 233-239.

15 Chiang CK, Ho TI, Hsu SP, Peng YS, Pai MF, Yang SY, Hung KY \& Tsai TJ. Low-density lipoprotein cholesterol: association with mortality and hospitalization in hemodialysis patients. Blood Purification 200523 134-140.

16 Heng D, Ma S, Lee JJ, Tai BC, Mak KH, Hughes K, Chew SK, Chia KS, Tan CE \& Tai ES. Modification of the NCEP ATP III definitions of the metabolic syndrome for use in Asians identifies individuals at risk of ischemic heart disease. Atherosclerosis 2006 186 367-373.

17 Cozzolino M, Galassi A, Biondi ML, Turri O, Papagni S, Mongelli N, Civita L, Gallieni M \& Brancaccio D. Serum fetuin-A levels link inflammation and cardiovascular calcification in hemodialysis patients. American Journal of Nephrology 200626 423-429.

18 Ketteler M, Bongartz P, Westenfeld R, Wildberger JE, Mahnken AH, Bohm R, Metzger T, Wanner C, Jahnen-Dechent W \& Floege J. Association of low fetuin-A (AHSG) concentrations in serum with cardiovascular mortality in patients on dialysis: a cross-sectional study. Lancet $2003 \mathbf{3 6 1} 827-833$.

19 Ix JH, Wassel CL, Kanaya AM, Vittinghoff E, Johnson KC, Koster A, Cauley JA, Harris TB, Cummings SR \& Shlipak MG. Fetuin-A and incident diabetes mellitus in older persons. Journal of the American Medical Association $2008300182-188$.

20 Lin X, Braymer HD, Bray GA \& York DA. Differential expression of insulin receptor tyrosine kinase inhibitor (fetuin) gene in a model of diet-induced obesity. Life Sciences 199863 145-153.
21 Vega GL, Chandalia M, Szczepaniak LS \& Grundy SM. Metabolic correlates of nonalcoholic fatty liver in women and men. Hepatology 200746 716-722.

22 Kalantar-Zadeh K, Block G, Humphreys MH \& Kopple JD. Reverse epidemiology of cardiovascular risk factors in maintenance dialysis patients. Kidney International 200363 793-808.

23 Dwyer JT, Larive B, Leung J, Rocco MV, Greene T, Burrowes J, Chertow GM, Cockram DB, Chumlea WC, Daugirdas J, Frydrych A \& Kusek JW. Are nutritional status indicators associated with mortality in the Hemodialysis (HEMO) Study? Kidney International 200568 1766-1776.

24 Honda H, Qureshi AR, Heimburger O, Barany P, Wang K, Pecoits-Filho R, Stenvinkel P \& Lindholm B. Serum albumin, C-reactive protein, interleukin 6 , and fetuin a as predictors of malnutrition, cardiovascular disease, and mortality in patients with ESRD. American Journal of Kidney Diseases 2006 47 139-148.

25 Enia G, Sicuso C, Alati G \& Zoccali C. Subjective global assessment of nutrition in dialysis patients. Nephrology, Dialysis, Transplantation 19938 1094-1098.

26 Yoshizumi S, Suzuki S, Hirai M, Hinokio Y, Yamada T, Yamada T, Tsunoda U, Aburatani H, Yamaguchi K, Miyagi T \& Oka Y. Increased hepatic expression of ganglioside-specific sialidase, NEU3, improves insulin sensitivity and glucose tolerance in mice. Metabolism 200756 420-429.

27 Wanner C \& Krane V. Non-high-density lipoprotein cholesterol: a target of lipid-lowering in dialysis patients. American Journal of Kidney Diseases 200341 S72-S75.

$28 \mathrm{Liu}$ J \& Rosner MH. Lipid abnormalities associated with end-stage renal disease. Seminars in Dialysis $20061932-40$.

29 Cressman MD, Heyka RJ, Paganini EP, O’Neil J, Skibinski CI \& Hoff HF. Lipoprotein(a) is an independent risk factor for cardiovascular disease in hemodialysis patients. Circulation 1992 $86475-482$.

30 Koda Y, Nishi S, Suzuki M \& Hirasawa Y. Lipoprotein(a) is a predictor for cardiovascular mortality of hemodialysis patients. Kidney International 199971 S251-S253.

31 Prichard SS. Impact of dyslipidemia in end-stage renal disease. Journal of the American Society of Nephrology 2003 14 S315-S320.

Received 3 January 2009

Accepted 16 February 2009 